\title{
Astragaloside IV rescues MPP+'induced mitochondrial dysfunction through upregulation of methionine sulfoxide reductase A
}

\author{
YUE LIU, LI CHONG, XIAOQING LI, PENG TANG, PENG LIU, CHEN HOU, XIN ZHANG and RUI LI \\ Department of Neurology, Shaanxi Provincial People's Hospital, Xi'an, Shaanxi 710068, P.R. China
}

Received July 15, 2016; Accepted April 28, 2017

DOI: $10.3892 /$ etm.2017.4834

\begin{abstract}
Methionine sulfoxide reductase (Msr) repairs oxidatively damaged proteins through acting as an antioxidant. Oxidative stress has been postulated to cause the mitochondrial dysfunction that is associated with aging and certain diseases, including Parkinson's disease (PD). The present study investigated the protective effects of astragaloside IV (AS-IV) on 1-methyl-4-phenylpyridinium $\left(\mathrm{MPP}^{+}\right)$-induced mitochondrial dysfunction through MsrA in PC12 cells. This revealed that oxidative stress reduced the expression of MsrA following $\mathrm{MPP}^{+}$treatment. AS-IV was demonstrated to protect PC12 cells from $\mathrm{MPP}^{+}$-induced oxidative damage through upregulating MsrA. MsrA expression was dependent on the Sirt1-FOXO3a signaling pathway. In addition, knockdown of MsrA reduced the protective effects of AS-IV, indicating that the antioxidant effects of AS-UV occurred through MsrA. These results suggest that AS-IV exerts antioxidant effects and regulates mitochondrial function. Thus, AS-IV may serve as an effective therapeutic agent for aging and PD.
\end{abstract}

\section{Introduction}

Oxidative stress is induced by an imbalance between the production and elimination of reactive oxygen species (ROS) and reactive nitrogen species (RNS) (1). Although ROS and RNS are generated under normal physiological conditions, numerous cellular functions are disturbed by the reaction of ROS/RNS with cellular components, including DNA, lipids and proteins (2-6). For example, sulfur-containing amino acids (methionine and cysteine) are sensitive to ROS (7). Mitochondria are a major source of ROS (8). The free radical

Correspondence to: Dr Yue Liu, Department of Neurology, Shaanxi Provincial People's Hospital, 256 West Youyi Road, Xi'an, Shannxi 710068, P.R. China

E-mail: june0420@sina.com

Abbreviation: MPP+, 1-methyl-4-phenylpyridinium

Key words: astragaloside IV, mitochondrion, methionine sulfoxide reductase A, oxidative stress $\cdot \mathrm{O}_{2}{ }^{-}$is produced by complex I and complex III of the electron transport chain (ETC) and released into the mitochondrial matrix (9). The mitochondrial dysfunction caused by oxidative stress and can result in cell loss leading to neurodegenerative diseases and ischemic brain injury (10). Thus, pro-oxidant antioxidant generation needs to be highly regulated (11).

Methionine sulfoxide reductase (Msr) A and B, which reduce free and protein-based methionine sulfoxides to methionine, are encoded by a single MsrA and three MsrB genes, respectively, in the mammalian genome $(7,12)$. Mammalian MsrA is expressed in the mitochondria, cytosol and nucleus $(13,14)$. Methionine oxidation and reduction serves an important role in cellular signaling, metabolism and oxidative stress under physiological and pathological conditions (15). MsrA repairs oxidatively-damaged proteins and functions as an antioxidant enzyme (16). MsrA has been identified to protect various cell types against oxidative stress-induced death $(17,18)$.

Astragaloside IV (3-O-beta-D-xylopyranosyl-6-O-betaD-glucopyrannosyl-cycloastragenol; AS-IV) is purified from the Chinese medicinal herb, Astragalus membranaceus (19). The molecular structure of AS-IV is illustrated in Fig. 1A. AS-IV has comprehensive pharmacological functions, including anti-inflammatory and antioxidative activity, and is able to reduce infarct size and improve post-ischemic brain function (20-22). However, few studies have investigated whether AS-IV prevents mitochondrial dysfunction via MsrA. The present study utilized a 1-methyl-4-phenylpyridinium $\left(\mathrm{MPP}^{+}\right)$-induced oxidative damage cell model to investigate this. $\mathrm{MPP}^{+}$is toxic and acts by interfering with oxidative phosphorylation in the mitochondria through inhibiting complex I, which induces oxidative stress $(23,24)$. $\mathrm{MPP}^{+}$can reproduce the clinical and pathological features of Parkinson's disease (PD) in animal models (25-27). Therefore, present study aimed to investigate the protective effects of AS-IV against $\mathrm{MPP}^{+}$-induced oxidative damage and the potential molecular mechanisms underlying these effects.

\section{Materials and methods}

Antibodies and reagents. Anti-MsrA (cat. no. ab16803), anti-forkhead box protein O3 (FOXO3a; cat. no. ab47409) and anti- $\beta$-actin (cat. no. ab6276) antibodies were purchased from Abcam (Shanghai, China). AS-IV (cat. no. 74777) was purchased from the National Institutes for Food and Drug 
Control (Beijing, China). Ex527 (cat. no. E7034), $\mathrm{MPP}^{+}$(cat. no. D048) and Protease Inhibitor Cocktail (cat. no. P8340) were purchased from Sigma-Aldrich (Merck KGaA, Darmstadt, Germany). TRIzol reagent (cat. no. 15596-018), Lipofectamine ${ }^{\circledR} 2000$ (cat. no. 11668-019), MitoTracker ${ }^{\circledR}$ Red CMXRos (cat. no. M-7512), CM-H2DCFDA (cat. no. C6827) and MTT (cat. no. M-6494) were purchased from Thermo Fisher Scientific, Inc. (Waltham, MA, USA). QuantiTect Reverse Transcription kit (cat. no. 205314) and QuantiTect SYBR $^{\circledR}$ Green PCR kit (cat. no. 204145) were purchased from Qiagen, Inc. (Valencia, CA, USA).

Cell culture, and $\mathrm{MPP}^{+}$-induced injury and AS-IV treatment. Rat adrenal gland pheochromocytoma PC12 cells were obtained from the Type Culture Collection of the Chinese Academy of Sciences (Shanghai, China). The cells were cultured in high glucose Dulbecco's modified Eagle medium containing $10 \%$ fetal bovine serum (cat. no. 12484-010, Thermo Fisher Scientific, Inc.) and $2 \mathrm{mM}$ L-glutamine (cat. no. 25030081, Thermo Fisher Scientific, Inc.) in a incubator at $37^{\circ} \mathrm{C}$ with $5 \%$ $\mathrm{CO}_{2}$. PC12 cells were randomly divided and treated with 1 , $10 \mu \mathrm{M}, 50$ or $100 \mu \mathrm{M} \mathrm{MPP}^{+}$for $24 \mathrm{~h}$. In the AS-IV treatment experiment, the $\mathrm{MPP}^{+}$-treated $\mathrm{PC} 12$ cells were simultaneously treated with $50 \mu \mathrm{M}$ AS-IV.

Cell viability assay. Cell viability was determined using the MTT assay. Cells were seeded in 96-well plates at a density of $1 \times 10^{4}$ cells/well. After MTT and AS-IV treatment, $0.5 \mathrm{mM}$ MTT was added into each well and the plates were incubated at $37^{\circ} \mathrm{C}$ with $5 \% \mathrm{CO}_{2}$ for $4 \mathrm{~h}$. Dimethylsulfoxide was added to each well in order to dissolved the formazan crystals and the absorbance at $570 \mathrm{~nm}$ was measured using a microplate reader. Cell viability was expressed as a percentage of the untreated control cells.

Western blot analysis. Cells were washed with PBS and resuspended in lysis buffer (cat. no. P0013G; Beyotime Institute of Biotechnology, Haimen, China) with a Protease Inhibitor Cocktail (cat. no. 04693132001; Roche Diagnostics, Basel, Switzerland; 1 tablet per $10 \mathrm{ml}$ ). The protein was quantified using a BCA Protein Assay (cat. no. 23225; Pierce; Thermo Fisher Scientific, Inc.). Protein samples (50 $\mu \mathrm{g}$ per lane) were separated by SDS-PAGE on a $10 \%$ gel, followed by electrotransfer onto polyvinylidenefluoride membranes. The blots were incubated with anti-MsrA (cat. no. ab16803; $1: 1,000$ ) and anti- $\beta$-actin (cat. no. ab6276; $1: 1,000)$ primary antibodies at $4^{\circ} \mathrm{C}$ for $12 \mathrm{~h}$. After washing with Tris-buffered saline-Tween 20, the blots were incubated with Goat Anti-Rabbit IgG H\&L conjugated to horseradish peroxidase (HRP; cat. no. ab6721; Abcam; 1:3,000) and Goat Anti-Mouse IgG H\&L conjugated to HRP (cat. no. ab6789; Abcam; 1:3,000) at room temperature for $3 \mathrm{~h}$. Protein expression was normalized to $\beta$-actin according to the gray scales by chemiluminescence, and quantified using a using a Gel Doc ${ }^{\mathrm{TM}} \mathrm{XR}+$ system version 4.0 (Bio-Rad Laboratories, Inc., Hercules, CA, USA).

Small interfering (si)RNA and plasmid transfection. MsrA and FOXO3a-specific siRNAs were synthesized by Sangon Biotech Co., Ltd. (Shanghai, China). The siRNAs sequences were as follows: MsrA-specific siRNA, 5'-CCAUGAAUCAUUUGC CAAAUCGCUU-3'; FOXO3a- specific siRNA, 5'-CAACCT GTCACTGCATAGT-3'; and negative control siRNA, 5'-CCA GCACUAACACCCAUCCCACAAA-3' (Sangon Biotech Co., Ltd.). A total of $1 \times 10^{6}$ cells were seeded in $60 \mathrm{~mm}$ plates and transfected with siRNA or plasmids using Lipofectamine 2000 according to the manufacturer's protocol and incubated at $37^{\circ} \mathrm{C}$ for $48 \mathrm{~h}$, with fresh medium added every $6 \mathrm{~h}$. Subsequently, the cells were collected for mRNA and protein extraction.

Reverse transcription-quantitative polymerase chain reaction (RT-qPCR) analysis of MsrA mRNA expression. Total cellular RNA was extracted from the cells using TRIzol reagent according to the manufacturer's protocol. cDNA was synthesized from total RNA using the QuantiTect Reverse Transcription kit according to the manufacturer's protocol. qPCR was performed using the QuantiTect SYBR Green PCR kit according to the manufacturer's protocol. The volume of PCR tube was $50 \mu 1$ including $25 \mu \mathrm{l}$ SYBR Green, $1 \mu \mathrm{l}$ primer A, $1 \mu \mathrm{l}$ primer B, $1 \mu \mathrm{l}$ cDNA and $22 \mu \mathrm{l}$ RNase-free water. The qPCR protocol was as follows: Denaturation at $95^{\circ} \mathrm{C}$ for $15 \mathrm{sec}$, annealing at $60^{\circ} \mathrm{C}$ for $30 \mathrm{sec}$, extension at $72^{\circ} \mathrm{C}$ for $30 \mathrm{sec}$ (40 cycles). This was followed by a dissociation step at $95^{\circ} \mathrm{C}$ for $15 \mathrm{sec}, 60^{\circ} \mathrm{C}$ for $15 \mathrm{sec}$, and then $95^{\circ} \mathrm{C}$ for $15 \mathrm{sec}$. The relative mRNA levels were normalized to $\beta$-actin and quantified using the $2^{-\Delta \Delta \mathrm{Cq}}$ method (28). Specific qPCR primers were synthesized by Sangon Biotech Co., Ltd. The primers for qPCR were as follows: MsrA forward, 5'-TCTGGGTCTTGA AAGGAGTGTA-3' and reverse, 5'-AGGTATTGCTGGTGG TAGTCTTC-3'; and $\beta$-actin forward, 5'-CCACTGCCGCAT CCTCTTCCTC-3' and reverse, 5'-CAGCAATGCCTGGGT ACATGGTG-3'.

ROS detection. CM-H2DCFDA, an ROS indicator, was used to measure the ROS production in PC12 cells. A total of $1 \times 10^{5}$ cells were inoculated into 24 -well plates. A working concentration of $5 \mu \mathrm{M}$ CM-H2DCFDA was produced and added to the plates, which were incubated at $37^{\circ} \mathrm{C}$ for $30 \mathrm{~min}$. The cells were washed with prewarmed PBS at $37^{\circ} \mathrm{C}$. After washing the cells, fluorescence was detected using a microplate reader $(495 / 520 \mathrm{~nm})$ and expressed as a percentage of the value of the untreated control cells.

Mitochondrial morphology staining and analysis. PC12 cells were cultured on poly-L-lysine-coated slides. A total of $1 \times 10^{5}$ cells were seeded into $24-$ well plates. PC2 cells were treated by $\mathrm{MPP}^{+}$and/or AS-IV in the no siRNA-interfering group and MsrA-knockdown group by siRNA. After treatment, $10 \mathrm{nM}$ MitoTracker Red CMXRos was added into the culture medium and the cells were incubated for $15 \mathrm{~min}$ at $37^{\circ} \mathrm{C}$ with $5 \% \mathrm{CO}_{2}$. After staining, the cells were washed with fresh prewarmed PBS and observed using a fluorescence microscope. The analysis was performed as described previously (29).

Statistical analysis. The statistical significance of differences between groups was analyzed using an unpaired Student's t-test or one-way analysis of the variance. GraphPad Prism software (version 5.01; GraphPad Software Inc., La Jolla, CA, USA). All data are presented as the mean \pm standard error of mean 

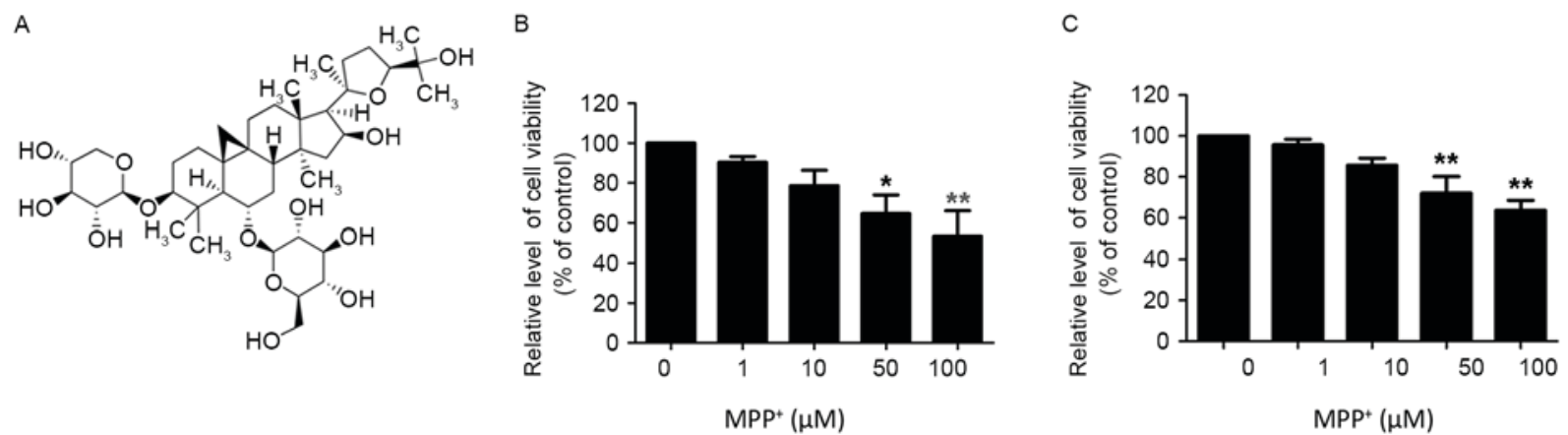

Figure 1. Protective effect of AS-IV against MPP+-induced oxidative damage. (A) Chemical structure of AS-IV. (B) PC12 cells were treated with increasing concentrations of $\mathrm{MPP}^{+}$for $24 \mathrm{~h}$. (C) AS-IV $-0 \mu \mathrm{M}$ ) treatment rescued cell viability following MPP treatment. ${ }^{*} \mathrm{P}<0.05$ and ${ }^{* * *} \mathrm{P}<0.01$ vs. the control group (one-way analysis of the variance). AS-IV, astragaloside IV; $\mathrm{MPP}^{+}$, 1-methyl-4-phenylpyridinium.

A
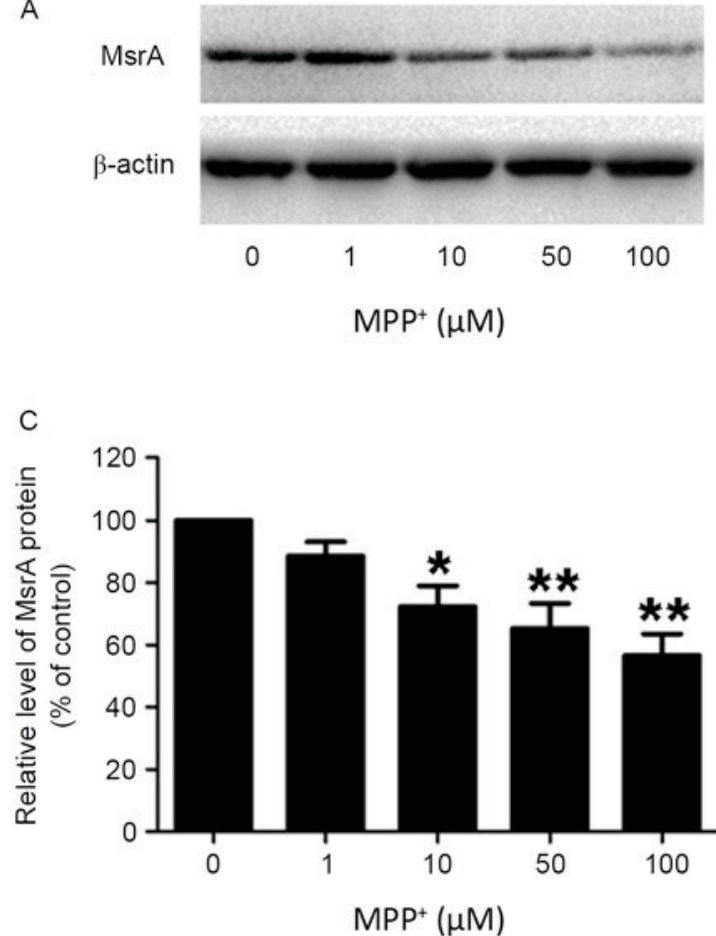

B
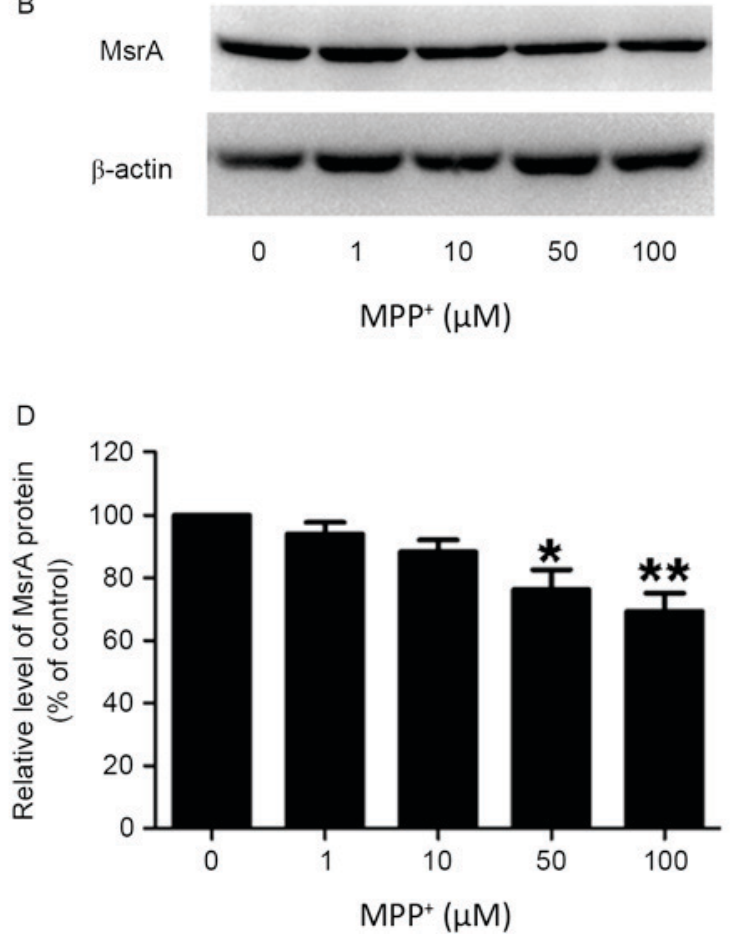

Figure 2. Protein levels of MsrA following oxidative damage by $\mathrm{MPP}^{+}$with and without AS-IV treatment. Western blots for MsrA after (A) MPP treatment, and (B) AS-IV and $\mathrm{MPP}^{+}$treatment. Densitometry analysis of western blots for MsrA after (C) increasing MPP ${ }^{+}$treatment, and (D) AS-IV (50 $\left.\mu \mathrm{M}\right)$ and increasing $\mathrm{MPP}^{+}$treatment. Simultaneous treatment with AS-IV attenuated $\mathrm{MPP}^{+}$-induced reductions in $\mathrm{MsrA}$ levels. ${ }^{*} \mathrm{P}<0.05$ and ${ }^{* *} \mathrm{P}<0.01$ vs. the control group (one-way analysis of the variance). MsrA, methionine sulfoxide reductase A; AS-IV, astragaloside IV; MPP+, 1-methyl-4-phenylpyridinium.

of three independent experiments. $\mathrm{P}<0.05$ was considered to indicate a statistically significant difference.

\section{Results}

AS-IV alleviates $\mathrm{MPP}^{+}$-induced oxidative damage in PC12 cells. To investigate the effect of AS-IV against oxidative damage, $\mathrm{PC} 12$ were treated cells with increasing $\mathrm{MPP}^{+}$concentrations as a model of oxidative stress. The MTT assay results revealed that cell viability was reduced with increasing $\mathrm{MPP}^{+}$ concentrations, with a significant decrease in cell viability to $53.7 \pm 12.4 \%$ with $100 \mu \mathrm{M} \mathrm{MPP}^{+}$compared with the untreated control group $(\mathrm{P}<0.01$; Fig. 1B). Treatment with $50 \mu \mathrm{M}$ AS-IV partially rescued the viability of $\mathrm{PC} 12$ cells treated with $\mathrm{MPP}^{+}$(Fig. 1C). AS-IV treatment significantly increased cell viability to $63.7 \pm 4.9 \%$ with $100 \mu \mathrm{M} \mathrm{MPP}^{+}$treatment compared with the control group, a 1.18 -fold increase $(\mathrm{P}<0.01$; Fig. $1 \mathrm{C})$.

$A S-I V$ rescues $M$ srA protein expression after $M P P^{+}$-induced oxidative damage. MsrA repairs oxidatively-damaged proteins and functions as an antioxidant enzyme $(16,18)$. To investigate whether MsrA is associated with the protective effect of AS-IV, protein levels of MsrA after $\mathrm{MPP}^{+}$-induced oxidative damage with or without AS-IV were measured using western blotting (Fig. 2). The results demonstrated that the protein levels of MsrA gradually decreased with increasing $\mathrm{MPP}^{+}$(Fig. 2A and C). AS-IV treatment alleviated the $\mathrm{MPP}^{+}$-induced decrease in MsrA protein levels, with MsrA returned to near normal levels in cells treated with $1 \mu \mathrm{M}$ and $10 \mu \mathrm{M} \mathrm{MPP}^{+}$(Fig. 2B and D). 
A

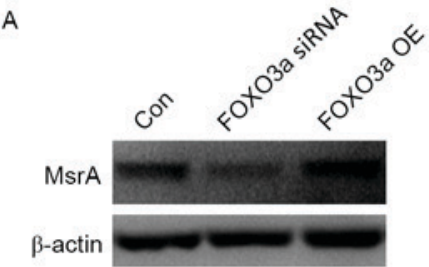

D

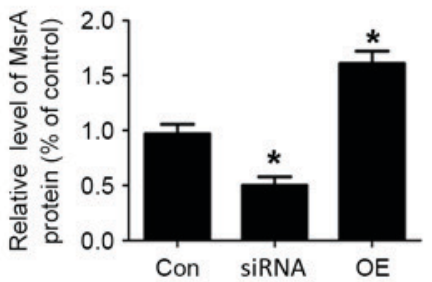

B

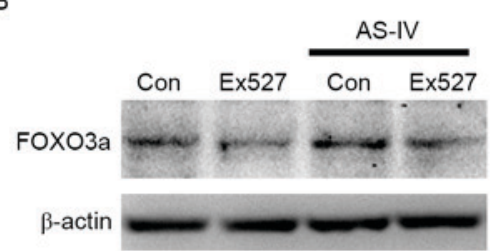

$E$

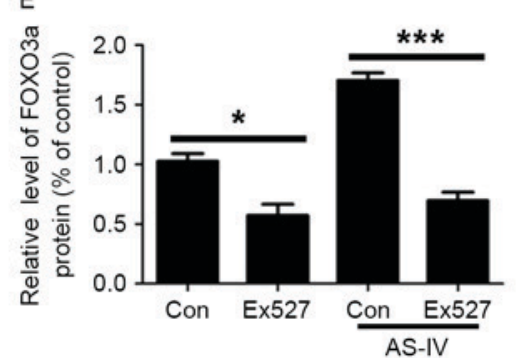

C

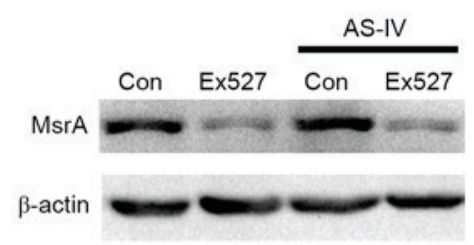

F

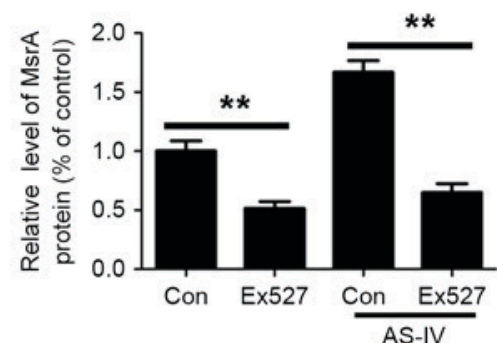

Figure 3. AS-IV increases MsrA expression through the NAD-dependent protein deacetylase sirtuin-1-FOXO3a signaling pathway. Western blot for (A) MrsA after FOXO3a-specific siRNA and OE treatment, (B) FOXO3a after $1 \mu \mathrm{M}$ Ex527 treatment with or without AS-IV, and (C) MrsA after $1 \mu \mathrm{M}$ Ex527 treatment with or without AS-IV. Densitometry analysis of western blots for (D) MrsA after FOXO3a-specific siRNA and OE treatment, (E) FOXO3a after $1 \mu$ M Ex527 treatment with or without AS-IV, and (F) MrsA after $1 \mu \mathrm{M}$ Ex527 treatment with or without AS-IV. ${ }^{*} \mathrm{P}<0.05,{ }^{* * *} \mathrm{P}<0.01$ and ${ }^{* * *} \mathrm{P}<0.001$ compared with the Con group (t-test). AS-IV, astragaloside IV; MsrA, methionine sulfoxide reductase A; FOXO3a, forkhead box protein O3, siRNA, small interfering RNA; OE, overexpression; Con, control.

AS-IV increases MsrA protein expression through the NAD-dependent protein deacetylase sirtuin-1 (Sirt1)-FOXO3a pathway. The underlying molecular mechanism of MsrA upregulation by AS-IV was explored. A previous study indicated that MsrA expression is regulated via the forkhead box protein/FOXO signaling pathway (30). Sirt1 regulates tyrosine hydroxylase expression and the differentiation of neuroblastoma cells via the FOXO3a signaling pathway (31). Whether Sirt1-FOXO3a could regulate the expression of MsrA in PC12 cells was assessed via siRNA treatment, Ex527 treatment and western blotting (Fig. 3). MsrA protein expression was significantly reduced by FOXO3a-specific siRNA, but significantly increased by FOXO3a overexpression, in PC12 cells compared with the control group (both $\mathrm{P}<0.05$; Fig. $3 \mathrm{~A}$ and D). Subsequently, Ex527, a Sirt1 inhibitor, was demonstrated to significantly reduce FOXO3a expression compared with the control group $(\mathrm{P}<0.05$; Fig. $3 \mathrm{~B}$ and $\mathrm{E})$. Similarly to FOXO3a-specific siRNA treatment, Ex527 also significantly inhibited MsrA protein expression compared with the control group $(\mathrm{P}<0.01$; Fig. $3 \mathrm{C}$ and $\mathrm{F})$.

MsrA decreases $\mathrm{MPP}^{+}$-induced oxidative damage via acting as an antioxidant. The effect of $\mathrm{Msr} \mathrm{A}$ on $\mathrm{MPP}^{+}$-induced oxidative damage was examined. Levels of MsrA mRNA and protein were significantly downregulated by MsrA-specific siRNA and significantly upregulated by an MsrA-overexpressing plasmid compared with the control group (both $\mathrm{P}<0.05$; Fig. 4A-C). Subsequently, ROS levels were detecting using CM-H2DCFD in cells treated with $\mathrm{MPP}^{+}$(Fig. 4D). ROS levels were significantly increased in the MsrA knockdown group compared with the control group $(\mathrm{P}<0.05)$. By contrast, ROS levels were significantly reduced in cells overexpressing MsrA compared with the control group $(\mathrm{P}<0.05)$. These results suggest that MsrA exhibits an antioxidant function against $\mathrm{MPP}^{+}$-induced oxidative damage in PC12 cells.
AS-IV inhibits $M P P^{+}$-induced mitochondrial fragmentation via MsrA. The phenomenon of mitochondrial fragmentation has been observed during oxidative stress, and there is an association between mitochondrial fragmentation and ROS release $(29,32)$. Fragmented mitochondria have been demonstrated to sensitize cells to apoptosis regulator BAX insertion and facilitate the release of apoptogenic factors (32). To determine whether AS-IV inhibits $\mathrm{MPP}^{+}$-induced mitochondrial fragmentation via MsrA, the density of mitochondria in PC12 cells was measured after treatment with $100 \mu \mathrm{M} \mathrm{MPP}^{+}$with or without $50 \mu \mathrm{M}$ AS-IV (Fig. 5). Imaging revealed that $\mathrm{MPP}^{+}$induced mitochondrial fragmentation and reduced the density of mitochondria (Fig. 5A, B, E and F), while AS-IV increased the density of mitochondria (Fig. 5C, D, G and H). In the presence of MsrA, AS-IV reduced the $\mathrm{MPP}^{+}$induced mitochondrial damage (Fig. 5B and C). By contrast, in the absence of MsrA, the protective effect of AS-IV was blocked (Fig. 5C and D). These data revealed that the protective effect of AS-IV against MPP ${ }^{+}$induced mitochondrial fragmentation was dependent on MsrA (Fig. 5I).

\section{Discussion}

ROS are primarily generated by mitochondria. The ROS $\cdot \mathrm{O}_{2}{ }^{-}$is produced by the ETC complexes I and III, released into the mitochondrial matrix and converted into $\mathrm{H}_{2} \mathrm{O}_{2}$ through dismutation by the antioxidant manganese superoxide dismustase (MnSOD) (33). However, excess $\cdot \mathrm{O}_{2}{ }^{-}$damages $\mathrm{Fe}-\mathrm{S}$ containing enzymes in the tricarboxylic acid cycle, disrupts ETC complexes and alters mitochondrial DNA (4,9,34). ROS damage cellular macromolecules, including DNA, proteins and lipids. Oxidation of free and protein-based methionine may alter protein structure and function, and cause mitochondrial dysfunction and the release of cytochrome $\mathrm{C}$, ultimately leading to apoptosis $(15,18,35)$. Increasing evidence indicates 


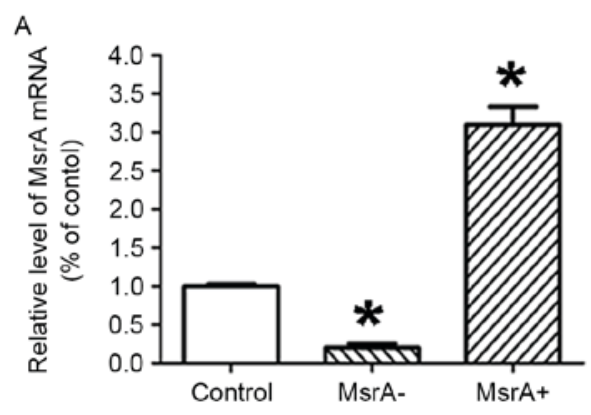

B
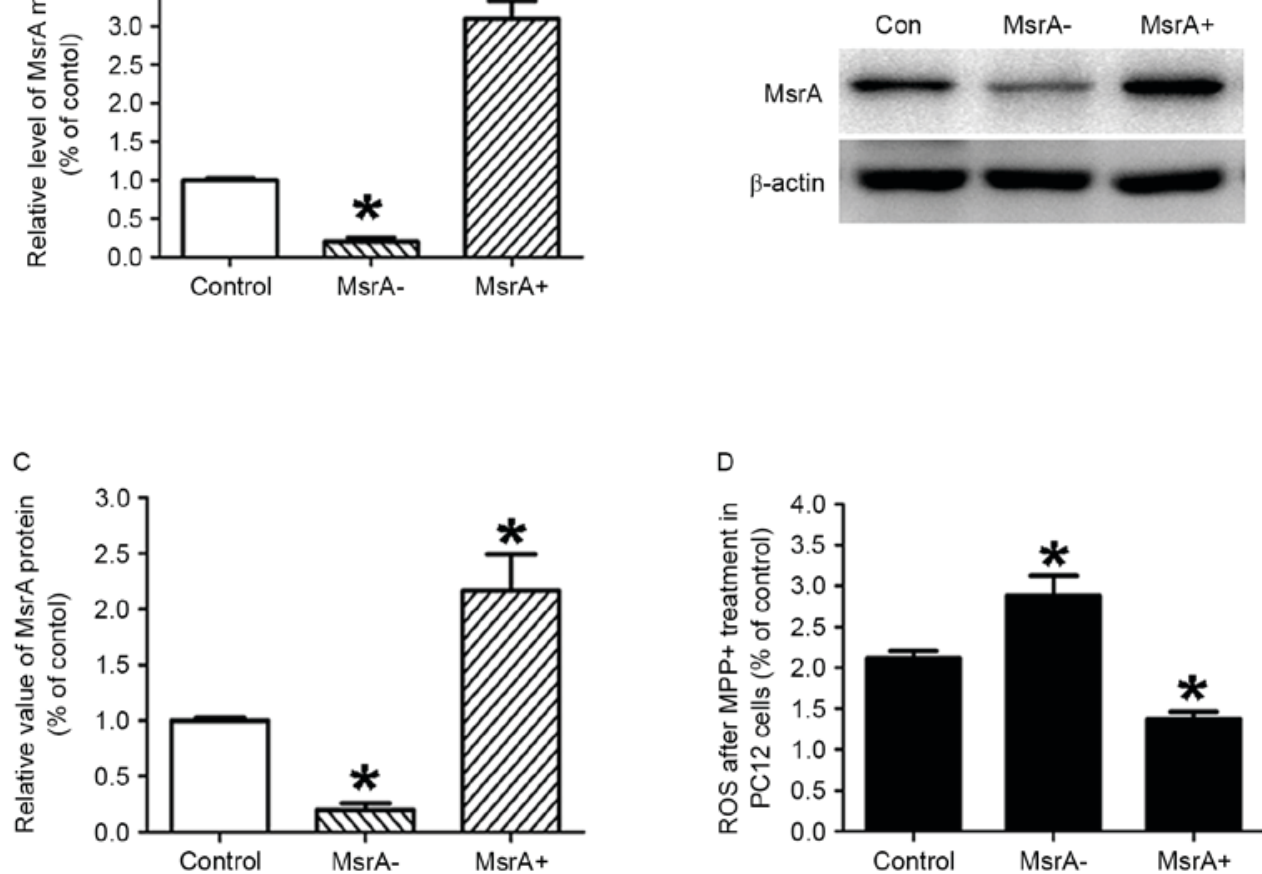

Figure 4. MsrA attenuates MPP+-induced oxidative damage via exerting an antioxidant effect. (A) mRNA level of MsrA after MrsA- or MsrA+. (B) Western blot and (C) densitometric analysis of the protein levels of MsrA after MrsA- or MsrA+. (D) ROS levels in cells treated with $100 \mu \mathrm{M} \mathrm{MPP}^{+}$after MrsA- or MsrA+. " $\mathrm{P}<0.05$ vs. the control group (one-way analysis of the variance). MsrA, methionine sulfoxide reductase A; MrsA-, MrsA-specific small interfering RNA treatment; MrsA+, MrsA overexpression; $\mathrm{MPP}^{+}$, 1-methyl-4-phenylpyridinium.

A

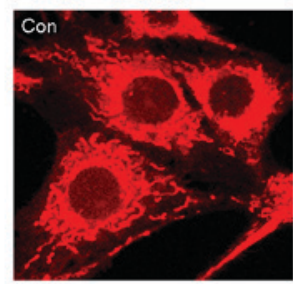

E

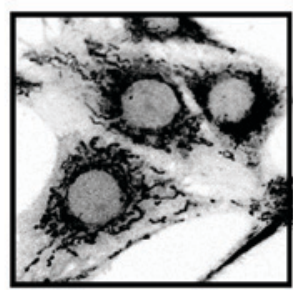

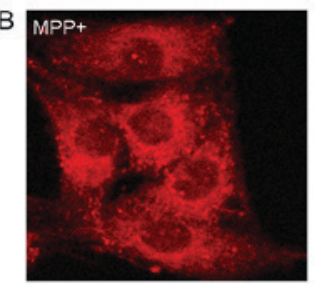
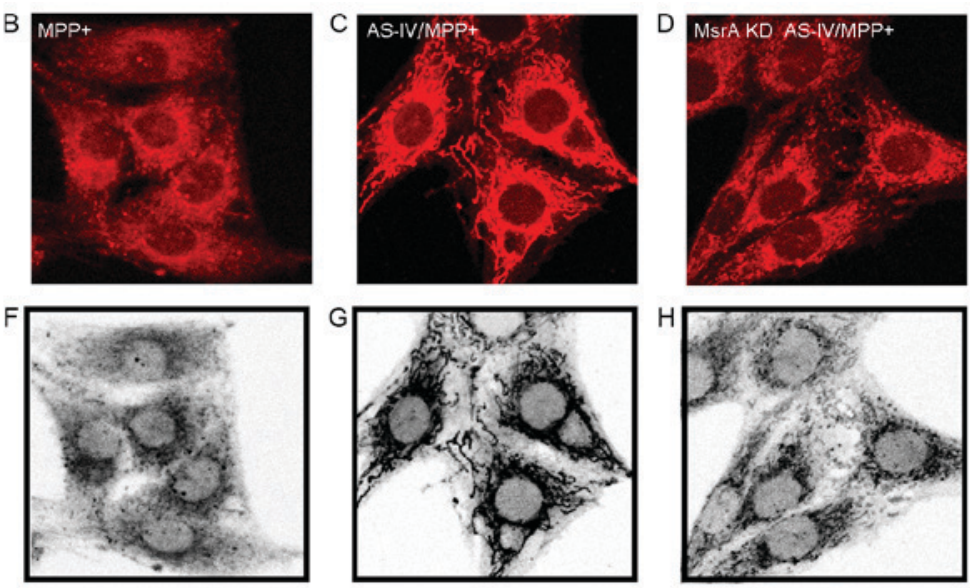

$$
\text { I }
$$

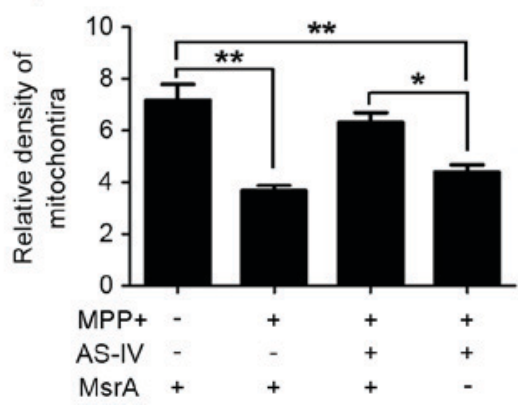

Figure 5. AS-IV reduced $\mathrm{MPP}^{+}$-induced mitochondrial fragmentation via MsrA. Micrographs of (A) the control group, (B) the $\mathrm{MPP}{ }^{+}(100 \mu \mathrm{M})$ treatment group, $(\mathrm{C})$ the AS-IV $(50 \mu \mathrm{M})$ and $\mathrm{MPP}^{+}$treatment group, and (D) the MsrA-specific siRNA treatment group. The micrographs were converted to black and white images of (E) the control group, (F) the $\mathrm{MPP}^{+}(100 \mu \mathrm{M})$ treatment group, $(\mathrm{G})$ the AS-IV $(50 \mu \mathrm{M})$ and $\mathrm{MPP}(100 \mu \mathrm{M})$ treatment group, and $(\mathrm{H})$ the MsrA-specific siRNA treatment group. (I) Quantification of relative mitochondrial density. ${ }^{*} \mathrm{P}<0.05$ and ${ }^{* *} \mathrm{P}<0.01$ vs. the control group (one-way analysis of the variance). AS-IV, astragaloside IV; MPP+, 1-methyl-4-phenylpyridinium; MsrA, methionine sulfoxide reductase A; siRNA, small interfering RNA; +, MsrA was existed and undisturbed in cells; -, MsrA in cells was knocked down by siRNA. 
that oxidative stress is an etiological factor for numerous diseases, including PD, Alzheimer's disease and brain ischemia $(4,9,36)$. Therefore, antioxidant intervention is a potential treatment option for these diseases.

$\mathrm{MPP}^{+}$is toxic and acts by interfering with the activity of tyrosine hydroxylase and thus oxidative phosphorylation in the mitochondria by inhibiting complex I of the ETC (37). $\mathrm{MPP}^{+}$ causes increased electron leakage from the ETC, leading to the production of $\cdot \mathrm{O}_{2}^{-}(24)$. $\mathrm{MPP}^{+}$thus exerts its toxic effects by decreasing ATP synthesis and inducing oxidative stress (37). $\mathrm{MPP}^{+}$can reproduce the clinical and pathological features of PD in animal models $(25,27)$. $\mathrm{MPP}^{+}$-induced neurodegeneration is specific to dopamine neurons and can be prevented by drug treatment with ginsenoside Rg1 or astragaloside IV $(38,39)$. Recent studies have demonstrated that certain botanical extracts have an antioxidant effects against oxidative-stress induced damage and PD $(38,40)$. Standardized extracts of ginsenoside Rg1 can efficiently terminate the toxic effects of MPTP in PD animal models (38). Rg1 activates the Wnt/ $\beta$-catenin signaling pathway in vivo and in vitro, thus exerting a protective effect against neurodegeneration (38). AS-IV has been used as an effective treatment for ischemia-reperfusion injury, myocardial infarction and type 2 diabetes $(21,39,41)$. The protective functions of AS-IV are attributed to an increased cellular content and activity of superoxide dismutase (SOD), and the inhibition of calcium pumps.

In a previous study, AS-IV was demonstrated to exert notable protective effects against $\mathrm{MPP}^{+}$-induced oxidative damage in SH-SY5Y neuroblastoma cells (41). However, the antioxidant mechanism of AS-IV remains unclear. In present study, AS-IV treatment was identified to increase the expression of MsrA via the Sirt1-FOXO3a signaling pathway and protect against $\mathrm{MPP}^{+}$-induced oxidative damage. These protective effects were dependent upon MsrA, indicating that the antioxidant effects of AS-IV are associated with MsrA. Previous studies have demonstrated that the loss of MsrA renders cells hypersensitive to damage by $\mathrm{H}_{2} \mathrm{O}_{2}$, nitrite and S-nitrosogluthatione, and results in the accumulation of higher levels of oxidized proteins $(13,15,17,18,42)$. In addition, AS-IV has been identified to confer increased resistance to oxidative stress $(18,21)$. These results indicate that AS-IV may regulate other potential antioxidative molecules, including SOD.

In the current study, AS-IV was observed to regulate mitochondrial function under conditions of oxidative stress via upregulating MsrA. The density of mitochondria was lower in the MsrA knockdown group compared with the control group under oxidative stress. AS-IV also prevented $\mathrm{MPP}^{+}$-induced mitochondrial fragmentation via MsrA, while knocking down MsrA attenuated this protective effect. This effect may be attributed to the fact that MsrA protects mitofusin from oxidation and maintains normal mitochondrial function (43). Since mitochondria are the primary source of ROS and are a major target of oxidative damage, mitochondrial protein dysfunction likely increases $\mathrm{MPP}^{+}$-induced oxidative damage. Thus, irreparable mitochondrial dysfunction may give rise to mitochondrial degradation, which ultimately leads to cell death.

In conclusion, the results of the present study indicate that AS-IV attenuates $\mathrm{MPP}^{+}$-induced oxidative damage in $\mathrm{PC} 12$ cells. The protective effect of AS-IV was associated with the upregulation of MsrA. Thus, acting through MsrA, AS-IV enhances the resistance of the mitochondria to oxidative stress. Therefore, AS-IV is a potential drug for the treatment of oxidative damage-induced disease.

\section{References}

1. Navarro-Yepes J, Zavala-Flores L, Anandhan A, Wang F, Skotak M, Chandra N, Li M, Pappa A, Martinez-Fong D, Del Razo LM, et al: Antioxidant gene therapy against neuronal cell death. Pharmacol Ther 142: 206-230, 2014.

2. Burgoyne JR, Mongue-Din H, Eaton P and Shah AM: Redox signaling in cardiac physiology and pathology. Circ Res 111: 1091-1106, 2012.

3. Steinberg SF: Oxidative stress and sarcomeric proteins. Circ Res 112: 393-405, 2013

4. Evans MD, Dizdaroglu M and Cooke MS: Oxidative DNA damage and disease: Induction, repair and significance. Mutat Res 567: 1-61, 2004.

5. Alam ZI, Jenner A, Daniel SE, Lees AJ, Cairns N, Marsden CD, Jenner $\mathrm{P}$ and Halliwell B: Oxidative DNA damage in the parkinsonian brain: An apparent selective increase in 8-hydroxyguanine levels in substantia nigra. J Neurochem 69: 1196-1203, 1997.

6. Ross BM, Moszczynska A, Erlich J and Kish SJ: Low activity of key phospholipid catabolic and anabolic enzymes in human substantia nigra: Possible implications for Parkinson's disease. Neuroscience 83: 791-798, 1998.

7. Kim HY: The methionine sulfoxide reduction system: Selenium utilization and methionine sulfoxide reductase enzymes and their functions. Antioxid Redox Signal 19: 958-969, 2013.

8. Babcock GT: How oxygen is activated and reduced in respiration. Proc Natl Acad Sci USA 96: 12971-12973, 1999.

9. Halliwell B: Oxidative stress and neurodegeneration: Where are we now? J Neurochem 97: 1634-1658, 2006.

10. Keeney PM, Xie J, Capaldi RA and Bennett JP Jr: Parkinson's disease brain mitochondrial complex I has oxidatively damaged subunits and is functionally impaired and misassembled. J Neurosci 26: 5256-5264, 2006.

11. Kaludercic N, Deshwal S and Di Lisa F: Reactive oxygen species and redox compartmentalization. Front Physiol 5: 285, 2014.

12. Kim HY and Gladyshev VN: Different catalytic mechanisms in mammalian selenocysteine- and cysteine-containing methionine-R-sulfoxide reductases. PLoS Biol 3: e375, 2005.

13. Kim HY and Gladyshev VN: Role of structural and functional elements of mouse methionine-S-sulfoxide reductase in its subcellular distribution. Biochemistry 44: 8059-8067, 2005.

14. Vougier S, Mary J and Friguet B: Subcellular localization of methionine sulphoxide reductase A (MsrA): Evidence for mitochondrial and cytosolic isoforms in rat liver cells. Biochem J 373: 531-537, 2003.

15. Kim HY and Gladyshev VN: Methionine sulfoxide reductases: Selenoprotein forms and roles in antioxidant protein repair in mammals. Biochem J 407: 321-329, 2007.

16. Luo $\mathrm{S}$ and Levine RL: Methionine in proteins defends against oxidative stress. FASEB J 23: 464-472, 2009.

17. Kantorow M, Hawse JR, Cowell TL, Benhamed S, Pizarro GO, Reddy VN and Hejtmancik JF: Methionine sulfoxide reductase A is important for lens cell viability and resistance to oxidative stress. Proc Natl Acad Sci USA 101: 9654-9659, 2004.

18. Tarrago L, Kaya A, Weerapana E, Marino SM and Gladyshev VN: Methionine sulfoxide reductases preferentially reduce unfolded oxidized proteins and protect cells from oxidative protein unfolding. J Biol Chem 287: 24448-24459, 2012.

19. Ren S, Zhang H, Mu Y, Sun M and Liu P: Pharmacological effects of Astragaloside IV: A literature review. J Tradit Chin Med 33: 413-416, 2013.

20. Zhang WJ, Hufnagl P, Binder BR and Wojta J: Antiinflammatory activity of astragaloside IV is mediated by inhibition of NF-kappaB activation and adhesion molecule expression. Thromb Haemost 90: 904-914, 2003.

21. Hu JY, Han J, Chu ZG, Song HP, Zhang DX, Zhang Q and Huang YS: Astragaloside IV attenuates hypoxia-induced cardiomyocyte damage in rats by upregulating superoxide dismutase-1 levels. Clin Exp Pharmacol Physiol 36: 351-357, 2009.

22. Tohda C, Tamura T, Matsuyama S and Komatsu K: Promotion of axonal maturation and prevention of memory loss in mice by extracts of Astragalus mongholicus. Clin Br J Pharmacol 149: $532-541,2006$. 
23. Testa CM, Sherer TB and Greenamyre JT: Rotenone induces oxidative stress and dopaminergic neuron damage in organotypic substantia nigra cultures. Brain Res Mol Brain Res 134: 109-118, 2005.

24. Betarbet R, Sherer TB, MacKenzie G, Garcia-Osuna M, Panov AV and Greenamyre JT: Chronic systemic pesticide exposure reproduces features of Parkinson's disease. Nat Neurosci 3: 1301-1306, 2000.

25. Friedemann T, Ying Y, Wang W, Kramer ER, Schumacher U, Fei J and Schröder S: Neuroprotective Effect of Coptis chinensis in MPP[Formula: see text] and MPTP-Induced Parkinson's Disease Models. Am J Chin Med 44: 907-925, 2016.

26. Wang S, He H, Chen L, Zhang W, Zhang X and Chen J: Protective effects of salidroside in the MPTP/MPP(+)-induced model of Parkinson's disease through ROS-NO-related mitochondrion pathway. Mol Neurobiol 51: 718-728, 2015.

27. Keane H, Ryan BJ, Jackson B, Whitmore A and Wade-Martins R: Protein-protein interaction networks identify targets which rescue the $\mathrm{MPP}^{+}$cellular model of Parkinson's disease. Sci Rep 5 : 17004,2015

28. Livak KJ and Schmittgen TD: Analysis of relative gene expression data using real-time quantitative PCR and the 2(-Delta Delta C(T)) Method. Methods 25: 402-408, 2015.

29. Koopman WJ, Distelmaier F, Esseling JJ, Smeitink JA and Willems PH: Computer-assisted live cell analysis of mitochondrial membrane potential, morphology and calcium handling. Methods 46: 304-311, 2008.

30. Chung H, Kim AK, Jung SA, Kim SW, Yu K and Lee JH: The Drosophila homolog of methionine sulfoxide reductase A extends lifespan and increases nuclear localization of FOXO. FEBS Lett 584: 3609-3614, 2010.

31. Kim MJ, Ahn K, Park SH, Kang HJ, Jang BG, Oh SJ, Oh SM, Jeong YJ, Heo JI, Suh JG, et al: SIRT1 regulates tyrosine hydroxylase expression and differentiation of neuroblastoma cells via FOXO3a. FEBS letters 583: 1183-1188, 2009

32. Brooks C, Cho SG, Wang CY, Yang T and Dong Z: Fragmented mitochondria are sensitized to Bax insertion and activation during apoptosis. Am J Physiol Cell Physiol 300: C447-C455, 2011.

33. Fukai T and Ushio-Fukai M: Superoxide dismutases: Role in redox signaling, vascular function, and diseases. Antioxid Redox Signal 15: 1583-1606, 2011.
34. Nicholls DG: Oxidative stress and energy crises in neuronal dysfunction. Ann NY Acad Sci 1147: 53-60, 2008

35. Weissbach H, Resnick L and Brot N: Methionine sulfoxide reductases: History and cellular role in protecting against oxidative damage. Biochim Biophys Acta 1703: 203-212, 2005.

36. Sanders LH and Greenamyre JT: Oxidative damage to macromolecules in human Parkinson disease and the rotenone model. Free Radic Biol Med 62: 111-120, 2013.

37. Yadava N and Nicholls DG: Spare respiratory capacity rather than oxidative stress regulates glutamate excitotoxicity after partial respiratory inhibition of mitochondrial complex I with rotenone. J Neurosci 27: 7310-7317, 2007.

38. Zhou T, Zu G, Zhang X, Wang X, Li S, Gong X, Liang Z and Zhao J: Neuroprotective effects of ginsenoside Rg1 through the Wnt/ $\beta$-catenin signaling pathway in both in vivo and in vitro models of Parkinson's disease. Neuropharmacology 101: 480-489, 2016.

39. Tu L, Pan CS, Wei XH, Yan L, Liu YY, Fan JY, Mu HN, Li Q, Li L, Zhang Y, et al: Astragaloside IV protects heart from ischemia and reperfusion injury via energy regulation mechanisms. Microcirculation 20: 736-747, 2013.

40. Lv L, Wu SY, Wang GF, Zhang JJ, Pang JX, Liu ZQ, Xu W, Wu SG and Rao JJ: Effect of astragaloside IV on hepatic glucose-regulating enzymes in diabetic mice induced by a high-fat diet and streptozotocin. Phytother Res 24: 219-224, 2010.

41. Zhang ZG, Wu L, Wang JL, Yang JD, Zhang J, Zhang J, Li LH, Xia Y, Yao LB, Qin HZ and Gao GD: Astragaloside IV prevents $\mathrm{MPP}^{+}$-induced SH-SY5Y cell death via the inhibition of Bax-mediated pathways and ROS production. Mol Cell Biochem 364: 209-216, 2012.

42. St John G, Brot N, Ruan J, Erdjument-Bromage H, Tempst P, Weissbach $\mathrm{H}$ and Nathan C: Peptide methionine sulfoxide reductase from Escherichia coli and Mycobacterium tuberculosis protects bacteria against oxidative damage from reactive nitrogen intermediates. Proc Natl Acad Sci USA 98: 9901-9906, 2001.

43. Park J, Choi H, Min JS, Kim B, Lee SR, Yun JW, Choi MS, Chang KT and Lee DS: Loss of mitofusin 2 links beta-amyloid-mediated mitochondrial fragmentation and Cdk5-induced oxidative stress in neuron cells. J Neurochem 132: $687-702,2015$. 